\title{
Contemporary landscape urbanism principles as innovative methodologies. The design of an armature of public spaces for the revitalisation of a shrinking city Olimpia Cermasi
}

University of Bologna, Italy

Department of Architecture

olimpiacermasi@gmail.com

\begin{abstract}
This paper explores the potentials of a series of Landscape Urbanism strategies for the revitalisation of a 'shrinking city', through the construction of an armature of public spaces and the reactivation of collective activities and social encounters. Looking through a series of theoretical approaches and case studies, mostly associated with Landscape Urbanism theory, this paper looks for typical interventions in the design of public spaces in a pattern of decreased socioeconomic activities. In addition, the paper provides an original contribution in the form of a review of a Studio research project developed during a Master of Science in Architecture and Urban Design at Columbia University, New York, in 2008. In more detail, the first part of the paper introduces the theme of shrinking cities with a series of theoretical approaches and a toolkit of possible interventions. The theoretical approaches derive from a new consideration of the contemporary city in the light of its spatial morphology. This is described through an excursus of previous studies and contributions to the analysis of the urban form and to the change of state that many cities are experiencing together with the decaying of their economic activities. A few case studies, beginning with the project by Oswald Mathias Ungers on the city of Berlin, further explore the role of open, 'left over spaces' in providing opportunities for a networked system of public spaces in contemporary urban conditions. The last part of the paper introduces a series of strategies that respond to similar situations on Governors Island, in New York, and the small town of Cohoes, in the State of New York. In particular, in the case of Cohoes, the proposal looks for opportunities in the existing downtown area- and articulates a series of strategies focused on the reprogramming and conversion of the existing 'left-over' open spaces- to turn them into 'public spaces'. These mechanisms aim to trigger several micro processes within the project, in order to follow through on the shrinking pattern in a positive, ecologic way. The last part of the paper offers a critique of the theories and case studies analysed, using these case studies as a way to test the theories already reviewed. Moreover, the conclusions introduce some definitions of networks from the theory of Space Syntax. In this way, the paper offers itself as a theoretical tool for the approach to shrinking cities and their evolutionary patterns through the design of an armature of public spaces.
\end{abstract}

Keywords: shrinking cities, landscape urbanism, programming open spaces, community, urban agriculture.

\section{To cite this article:}

Cermasi, O.. (2017). Contemporary landscape urbanism principles as innovative methodologies: the design of an armature of public spaces for the revitalisation of a shrinking city. The Journal of Public Space, 2(2), I I I- I 26. DOI: 10.5204/jps.v2i2.97

This article has been peer-reviewed and accepted for publication in The Journal of Public Space. Please see the Editorial Policies under the 'About' section of the journal website for further information. 


\section{Introduction}

When approaching the topic of revitalising a decaying town through the design of its public spaces, we have to take into consideration the main theme of shrinking cities, which involves a great body of both theoretical and design work on several case studies, beginning with micro-interventions on small towns and moving to wide- and sometimes only idealistic scenarios- applied to major cities such as Berlin or Detroit. First of all, the contemporary conditions of cities with decaying urban life require a new conceptualisation. Contemporary cities, in general, have experienced a general process of decentralisation due to the development of a new, diffused model of production activity. This new, decentralised urban condition can be defined as 'post-industrial'. Due to the dismantling of the industrial industry, many industrial cities have developed into shrinking cities. As Graham Shane (2005) explains, the Landscape Urbanism discussion stemmed from the reality of Detroit provides the most significant example of a shrinking city. A profound understanding of what constitutes the material of the post-industrial city and new design methods were required, especially in comparison to those applicable to the traditional and historical European city, with its clear distinction between 'built environment' and 'open spaces', and between 'city' and 'countryside'. The Landscape Urbanism discussion responded to this necessity by proposing, on the one hand, a new understanding of the American post-industrial city, and, on the other hand, a series of strategies "defining phases in time rather than defined forms, and considering landscape as a tool for growth patterns under conditions of uncertainty" (Smets, 2002, cited in Cermasi, Psarra, 2013: I). Most importantly, Landscape Urbanism theory inherits the description of the contemporary city as a 'networked system', with a transportation infrastructure interconnected with a significant amount of open spaces. This paper explores the potentials of this form of a 'network of open spaces and connections' to become an armature of public spaces in a city with a shrinking pattern.

When looking for theoretical conceptualisations to describe what a shrinking city is, it is necessary to take into consideration both the two phases of growth and shrinkage: on the one hand, urban growth occurring as a result of industrial activities, resulting in a diffused pattern of urbanisation, and, on the other hand, urban shrinkage, determined by the dismantling of industrial activities. Without the first phase, one cannot explain the second. Firstly, one needs to acknowledge the new, diffused form of urban growth derived from industrial development. Secondly, one needs to understand the new urban condition of a city that is dealing with a decaying economy, the dismantling of industries and the creation of a particular pattern of breaking down urban centres, and as a result, a loss in population due to this decay and a marked abandonment of entire complexes of workers' housing quarters. Somehow, it could be said that the problem of shrinking cities lies in the diffused pattern of urbanisation derived from post-war industrial activities, considering that not all industrial cities developed into shrinking cities. This could be explained by the degree of density and interconnection of different cities' urban fabric. Dense and well interconnected cities seem to survive the dismantling of industrial activities.

As an example, as explained by Amanda Pluviano and Sophia Psarra (20I4), both Turin and Detroit "are characteristic examples of manufacturing decline, having experienced the rise and weakening of automotive industries in the twentieth century. Both were defined by Fordism, $a$ socioeconomic model, a manufacturing management system and a 'total way of life', encompassing mass production and consumption (Harvey, 1990, cited in Pluviano, Psarra, 2014: 394). Moreover, "since the 1970s the two cities have differed radically" (Pluviano, 
Psarra, 2014: 394). The two authors analyse the two cities with Space Syntax, in order to investigate the way they compare spatially, in regards to industrial distribution. Space syntax, a theory and a method of analysing architecture and urban patterns in terms of their systems of relation, allows us to analyse the street networks of Turin and Detroit in different moments in time and overlay these onto the distribution of industries. The findings of this study are very useful to this discussion.

Both cities experienced a distribution of industries beyond the urban centre, but evolved very differently after 1970. On the one hand, it seems that Turin managed to evolve together with the changing industrial distribution, due to the integrated urban network that allowed new land uses when the industries migrated to the periphery, while, on the other hand, the decentralisation of industries and the suburbanisation of Detroit had negative consequences for the residential street network. In particular, Detroit was a lively American economic centre, in which the urban network was functioning according to the evolution of economic activities, until the decentralisation of industries required the construction of highways and freeways that extended the urban network but, at the same time, cut the urban fabric in pieces. What was developing as a flourishing industrial city, until the evolution of production into the Fordist model, developed into a whole, different urban pattern after the 1970s. The dismantling of its industrial activities created holes in the urban fabric of the city centre, that was already separated by the highways that were constructed following the general pattern of decentralisation of production activities and which acted as physical barriers. As Sophia Psarra (20I4) explains, the street network itself contributed, together with the dismantling of the industries, to segregate the urban fabric of the city centre. In fact, Detroit now consists of a decaying urban centre, surrounded by wealthier peripheral quarters (Pluviano, Psarra, 2014).

To conclude, it is obvious that not all post-industrial cities are shrinking cities, but in general, a shrinking city was previously an industrial city, that, at some point in time, suffered as a result of changes in economic patterns and industrial production and couldn't adjust to them. This failure to adjust to changes in production methods, and, more in general, to declining economic patterns is apparent both in terms of the urban fabric of a shrinking city and its pattern of connections. Detroit, in particular, was chosen as a model by Landscape Urbanism, of a new urban form- the post-industrial, American city- necessitating a particular focus. Together with Landscape Urbanism, other theoretical contributions wished to define the evolution of the pre- industrial urban forms in terms of urban growth, before, and urban shrinkage, afterwards. The next section of the paper provides a bibliographical review and a comparison of all these approaches, wishing to provide a path to a Landscape Urbanism theory for shrinking cities.

\section{The path to a Landscape Urbanism theory for shrinking cities}

As explained by Francesco Indovina (1990), the way in which many cities have developed into diffused cities constitutes not only a form of urban growth, but an evolution into a different 'state'. In fact, as I have explained in the paper named "Space Syntax, Landscape Urbanism, and the peri-urban condition. A theoretical tool through Space Syntax and Landscape Urbanism", published in 2013 with Sophia Psarra, when new forms of urbanisation derived from industrial growth resulted in new and alternative territorial identities, 'traditional concepts and distinctions between 'urban/rural', 'centre/periphery' had to be revised, as they were in effect influenced by the old models of urbanisation and 
perception" (Cermasi, Psarra, 2013: 2) . The paper describes, in its introduction, how Graham Sahen (2005) "traces the evolution of cities from the traditional, Eurocentric definition either as dense settlements distinct from the countryside or as broken beyond their former borders due to the industrial revolution, to a third conceptual and normative model" (Cermasi, Psarra, 20I3: 2). Moreover, as Sophia Psarra and I explain in the paper, in the book entitled Recombinant Urbanism (2005), "Shane analyzed this particular 'organic' city form, alongside the Ecological City, and the catalog of heterogeneous urban systems proposed by Kevin Lynch in "Good City Form", in 1984" (Cermasi, Psarra, 2013: 2). As the paper explains, Shane (2005) defines the work of Kevin Lynch as a step forward towards a new conceptualisation of cities. In particular "Kevin Lynch invented a terminology of heterogeneous urban systems to deal with the new urban situation, providing tools for the discussion of what later critics termed the 'reverse city' (Viganò) or 'net city' (Oswald), which are ultimately descended from Frank Lloyd Wright's Broadacre City, the city claiming vast landscapes". (Shane, 2005: 9). In fact, in contrast to the Modernists, that criticised both the sprawling determined by the industrial revolution and the pre-existing historical centres, Lynch provided a definition for the contemporary city by developing a conceptualisation of the urban network, defined by Shane (2005) as "a complex structure, with compressed nodes of activity and areas of widespread sprawl, that vary from low-rise development to the agricultural settlements that supports city life" (Shane, 2005: 27). Moreover, Shane assumes that "the form of 'sprawl' as the one envisioned by Wright for Broadacre City, with the landscape merging together the city with the countryside, was considered by Lynch as a positive evolution towards a new, 'organic' city model"' (Cermasi, Psarra, 20I3: 2).

Proceeding with an excursus on the analysis of the urban form, and of the evolutionary processes of cities in relation to their economic patterns, I will move forward from the organic city model, corresponding to a moment of economic growth and industrial expansion, to the theoretical and design approaches applied to cities exhibiting aspects of decay both in terms of their economic activities and their social patterns. In particular, I will look for concepts that can be placed in relation to the re-activation and public use of a 'common ground'. When tracing a possible trajectory of the Landscape Urbanism discussion, it can be argued that the theoretical understanding of post-industrial, American cities as 'reserves' of open spaces stemmed from another discussion, on postwar urban conditions, traceable in the work of Oswald Mathias Ungers on the city of Berlin, which he developed while working at Cornell University. In particular, "The city in the city: Berlin, a green archipelago" is the title of the publication in which, in 1977, Oswald Mathias Ungers, Rem Koohlaas, Peter Riemann, Hans Kollhoff and Arthur Ovaska, presented the results of research that focused on the creation of an intellectual approach to shrinking cities. Oswald Mathias Ungers and his colleagues presented a model of intervention which opposed the popular trends of reconstruction of the time: the city of Berlin was envisioned, in fact, as a polycentric urban landscape. This conceptual project constituted an advancement where it exchanged the 'design for the growth' approach for new approaches. As explained by Jasper Cepl, the study by Oswald Mathias Ungers was considered to be one of the most important planning concepts for an 'ideal city' (2006). West Berlin was experiencing a massive economic crisis during the 70's, and the whole city had been rebuilt in a fragmentary way, with empty lots all over. It was difficult to see the continuity between the physical remains of the post war years. In a moment when architects and urban designers were trained to build for large numbers, as an incipient population increase was expected, Oswald Mathias Ungers embraced the challenge to 
reverse this perspective and start conceiving methods of 'controlled decrease'. The project on Berlin, in particular, took into consideration the physical constraint: the West side could not decrease in size, as the wall had fixed its borders. Consequently, the idea was to preserve specific zones of the city that retained interesting characteristics, to complete those zones and on the contrary, to demolish the other superfluous areas that worked badly both in terms of the architectural quality and the patterns of social interaction. This way, the liberated enclaves would combine into an 'urban archipelago' of islands connected to each other over a background 'lagoon'. This background could be, in subsequent phases, gradually re-transformed into a natural environment, or possibly agricultural land, without considering rebuilding. The criteria for selecting which areas should be preserved considered their extremely different structures and fabrics, and particular morphological features that could be developed further. What Ungers envisioned, in conclusion, was a collection of possible ideal cities, divided by 'strips of green'. Most importantly, this vision was followed up with the new interpretation of the urban form as a 'networked reality' that ideally continually moves forward according to the models previously described. As a result, this project provided inspiration on preserving a series of existing public spaces in a city that could no longer support its own size with its economic activities, and reinforced those public spaces by selectively reducing the importance of other areas, not so relevant for public activities and collective uses. Those activities are considered by Ungers as being strongly related to the morphological aspects of those selected areas when compared to others. Another relevant aspect of the project is the necessity to provide actual connections between those areas, in order to construct a network of public spaces. In fact, Oswald Mathias Ungers was influenced by the reality of the American cities, and imagined a scenario of "an ideal city that integrates the experience of the American city, with its extensive highway networks and endless suburban spaces, with the ideal forms of the European city with its dense public spaces" (Cepl, 2006).

This approach to the city of Berlin introduces new means of understanding cities with shrinking patterns and at the same time new conceptual tools that provide a theoretical background for new projects, strategies, and interventions. The project for Berlin by Oswald Mathias Ungers could seem idealistic and not applicable as a practicable policy: as urban building land is often in private hands, the criteria of 'dis-urbanisation' of certain areas and not others could seem arbitrary. What is very inspiring though, as a practical tool, is the aspect of a 'reversed perspective' between the built environment and the open spaces, and, as mentioned before, the idea of a city as a 'networked system' where the movement network infrastructure ties together different areas through its open spaces. As Rem Koolhaas designed a proposal for the new town Melun-Senart in France, he declared that the urban archipelago project had inspired his concept of a system of green belts and corridors- described as 'active voids'- as the main determining elements of the project- on a background of 'urban islands'. The theoretical work of Pierre Donadieu, even if in a very different form, also proposes a reversed approach compared to the one derived from the historical perception of the European city, considered as a 'compact entity' physically separated from the rural landscape. In fact, Donadieu argues, that as it is not possible anymore to build 'the city in the countryside', it is now time to transform cities into an innovative 'rural urbanity'. In this sense, those voids that are 'left over' in the contemporary city can become the structuring armature of a new urban form, as long as they remain open spaces: "what if we built the urban fabric starting from its open spaces and 
the rural areas, instead of trying to control the growth with green belts and barriers?" (Donadieu, 2006).

In this sense, landscaping emerges as a model for contemporary urbanism, capable of integrating new models into the mutability of the contemporary city. When approaching the topic of a city with decaying economic activity, a reduced population, and a shortage of possibilities for social interaction, it seems that any possible intervention should work on reconfiguring what is already there, and on promoting strategies geared towards the reactivation of some form of urban life. Working on a network of open spaces and on interrelated systems incremented by infrastructural networks, means contrasting a form of stagnation consequent to the economic crisis, with an overlay of different strategies. When Charles Waldheim organised the exhibition entitled "landscape urbanism", in 1997, several American cities where still experiencing a massive crisis in the industrial sector, that lasted over twenty years, and were presented with an abundance of abandoned workers' housing, entire vacant areas and redundant commercial strips in mostly deserted down towns. The main concept of the exhibition was that the landscape could become a saviour for this condition and, in the words of Graham Shane (2006) "replace architectural form as the primary medium of city making" (058).

The interpretation of this post-industrial urban form enlightened the left-over void spaces of the city as new, potential commons. In fact, those terrain vagues could be connected, reactivated, and reprogrammed, founding a new "interstitial design discipline, operating in the space between buildings, infrastructural systems, and natural ecologies" (Shane, 2005: 059). As Shane explains, in the design activity of Field Operations, James Corner's professional practice, it is possible to trace a concept of a "performative urbanism, based on preparing the setting for programmed and unprogrammed activities on common land" (pag. 059). When approaching the theme of the abandoned downtown areas of former industrial centres, James Corner proposes the concept of "landscraping", as a strategy for approaching the shrinking aspect of Detroit documented in the publication named "Stalking Detroit", published in 200I. (Shane, 2006: 059). As explained by Graham Shane (2005), the architect interprets the creation of these inner voids of cities like Detroit as the result of the industrial organisation and consequent territorial evolution, and conceives the resultant voids as constructions produced by an industrial logic and as 'reserves of indeterminacy' and places of potential action. This logical and performative future action, as in the past, will emerge from social codes and conventions that regulate the relationships between urban stakeholders or actors in industrial societies $(059,060)$. According to Shane (2005), these codes become embedded in infrastructural regimes that are best depicted as diagrams of organisation: these diagrams show the mechanism necessary for something to be enacted, including erasure (pag. 058-059). In addition, Charles Waldheim proposes a Landscape Urbanism strategy for Detroit in a project named "Decamping Detroit", envisioning four stages in which the land would be decommissioned from city control (Shane, 2005: 059). In particular, these stages are named: "Dislocation (disconnection of services), then Erasure (demolition and jumpstarting the native landscape ecology by dropping appropriate seeds from the air), followed by Absorption (ecological reconstitution of part of the Zone as woods, marshes, and eropic village like enclaves)". (Corner, 200 I: I22-I 25 cited in Shane, 2006: 059).

According to these theories, when conceiving a toolkit of strategies for a shrinking city, taking into consideration the decaying economic activities, and the indeterminacy of its future evolution, a model based on a formal approach alone does not provide a remedy. 
In fact, the approach of Landscape Urbanism is somewhat distant from both the postmodernist and New Urbanism approaches, where it proposes more open-ended, strategic models. In fact, Charles Waldheim (2005) explains that the post-modernist critiqued the modernist for not creating meaningful and livable public spaces and for not taking into consideration the city "as an historical construction of collective consciousness" (038). It was however post-modernist architecture, that could not address the reality of the new, post-industrial urban condition, and while producing incredibly scenographic architecture, couldn't solve the 'crisis of urban life' in the conditions already explained in the first part of this paper. In fact, in taking European precedents for traditional city form, postmodern architects proposed designs featuring sometimes spectacular individual buildings, however, according to an absent context, and without producing significant changes in the use of the public spaces that they would create. According to Charles Waldheim, this practice seems to be a cultural regression: in fact, he argues that "the indeterminacy and flux of the contemporary city, and the bane of traditional European city making" are precisely the aspects explored in recent works on Landscape Urbanism and are more related to a modernist, rather than post-modernist approach to the contemporary city in relation to its public spaces (Waldheim, 2006: 039). Waldheim proposes Barcelona as a case of how the approach to public space has changed from a perspective which considers public spaces in terms of plazas, boulevards, etc, as the elements of the traditional city centre (during the 90's) to a new approach, featuring experimentation on how large-scale infrastructural landscapes can influence the redevelopment of a city. In fact, Barcelona's most recent urban project involves the redevelopment of airports, logistical zones, industrial waterfronts, metropolitan river ways, etc. Waldheim (2005) explains that, by the mid ' 90 s, both Rem Koolhas and Kenneth Frampton, usually very distant, were occupying a similar position on this subject, by declaring that landscape, rather that architecture, was mostly capable of ordering contemporary urban patterns. It is "landscape rather than object formalism" that can overcome the fragmentary aspect of the contemporary city (042).

In fact, the landscape urbanism theory provides interesting approaches in terms of the definition of a process of 'adaptation' of cities to their uncertain conditions. This openendedness, flexibility, and adaptation to temporal changes, are all principles of landscape design that can be employed in urban design. In more operative terms, the strategies include the staging of horizontal surfaces, defined by James Corner (2005) as "the preparation of a ground plane, the 'field' of action" (030), and the creation of networks of connections between those surfaces and the rest of the city, resulting in the preparation of a common ground that can accommodate different uses and events in time. Charles Waldheim (2006) presents the 1982 Competition for the Parc de la Villette as an example of how the design of a public space can "orchestrate a urban program as a landscape process" (040). This very well-known competition invited architects to submit ideas for a new 'Urban Park for the $21^{\text {th }}$ Century', that would occupy a wide stretch of land consisting of 125 acres, remaining as a result of the demolition of one of Paris' largest slaughterhouses. The former industrial site was expected to be replaced with a new park. As Waldheim (2006) explains, on the one hand, the project by Bernard Tschumi uses the previously explained landscape principles- including the layering of horizontal surfaces under a network of connections- as the preparation of a 'common ground' adaptable to multiple uses. This common ground can be used to order evolving arrangements of urban activities, a complexity of programs and social changes over time. The interest was, of 
course, to re propose 'event' and 'program' as the main concern when designing a public space, in opposition with the longstanding interest in stylistic issues that were dominating the architectural discourse of the postmodern era. On the other hand, the project by Rem Koolhaas proposes a variation on this concept, with the design of a series of "parallel strips of landscape" (Waldheim, 2006: 04I), recalling different uses and programs to be juxtaposed yet not necessarily have them interacting. Both these new concepts of parks shared the programmatic indeterminacy of their future uses. As Waldheim (2006) concludes, the infrastructure of the park, in both projects, provides a flexible, nonhierarchical, layered and strategic design, capable of accommodating events, public life and multiple uses (040-04I). This kind of project represents perfectly the typical intervention undertaken on a post-industrial area, with the replacement of left-over urban voids with intensely programmed public spaces. The proposals by Rem Koolhaas and Bernard Tshumi both constitute precedents for the concept of applying landscape design principles to the urban scale for the transformation of a decaying area. In other words, both of the two architects use landscape as an articulate medium to create an urban infrastructure. This infrastructure is made up of a pattern of development of horizontal surfaces and a network of connections, that will provide a stage for future collective activities and public events.

As this paper explores, the potential in transforming existing under-utilised open spaces into public spaces, as a tool for contrasting a crisis in the economy and, consequently, the social activities of a city, a scenario depicted in "Ecological reconfiguration of an urban center" constitutes an interesting contribution. The project by Ecosistema Urbano for the city of Philadelphia was selected from among five finalists by the Van Alen Institute, NY and the city of Philadelphia, as part of a competition they had launched in 2006. The objective was to regenerate approximately 40,000 urban voids, and in this case, the act of revitalisation of downtown Philadelphia needed to be a pervasive and diffused intervention. This approach differs from the approach undertaken in the case of la Villette and others involving the redevelopment of a former industrial area. In this case, the project proposed to employ a form of 'urban acupuncture' and proceed with interstitial insertions of 'urban catalysts' on a series of parallel corridors. The urban catalysts involve several participatory activities, in order to develop an economically-viable landscape, and to generate a strategic mechanism as a starting point for the self-reparation of the urban fabric. Light and demountable structures are strategically placed in areas with a high percentage of urban-voids, a short distance away from each other. The reactivation of the corridors would involve the re-programming of existing buildings, sometimes necessitating a retrofitting for accommodating new uses. The corridors interconnecting these new places of interest, in terms of social and cultural activities, would become the new public spaces of a revitalised area, thanks to the affluence of a mixture of different users. The corridors also demanded an intervention strategy based on the concentration of budget and effort in order that they might be turned into a sort of structural-line of program and activities. Moreover, the project necessitated a strategy for the reconfiguration of the existing connections into a new form of ecological mobility. By regenerating the networks of social, environmental, and physical elements, the project aimed to revitalise a decaying downtown area and transform it into a flourishing, livable urban community. The city of Philadelphia, with its strong history of citizen participation, would then contribute to developing a sustainable and economically-viable landscape. Surely, this case study inherited and heeded many of the lessons that were learned 
throughout the previous case studies. The idea of working within the existing patterns, without building new architectural objects, and implementing community participation strategies, is a starting point for a series of methodologies of intervention that can be applied to other case studies. As final examples, I will present two school projects which employ landscape urbanism strategies on two different shrinking scenarios: Governors Island in New York and Cohoes, a small former industrial town in upstate New York.

\section{Governors Island and Cohoes: the design of an armature of public spaces}

The last part of this paper presents a Studio project developed during a Master in Architecture and Urban Design at Columbia University in 2008. The Studio, directed by Mojdeh Bartloo, was assigned two sites to develop strategies for creating a form of "zero state", intended as a state of balance, in the context of abandonment, economical shrinkage, and reducing population. The two sites, very different from one another, were Governors Island in Manhattan and Cohoes, a former centre for the textile industry, located in Upstate New York.

Governors Island was once a military base. The prohibition of introducing residential uses resulted, in turn, in disincentives for other uses, as the activities taking place on the island were limited to recreational biking. In 2006, GIPEC launched an international competition for the design of the Island's 97 acres of park and public spaces. Conversely, the Urban Design Studio project, on the other hand, looked for a more efficient use of the island's resources, as turning the whole island into a park didn't seem to be an efficient strategy. Located in downtown Manhattan, Governor's Island is very close to the city but can only be reached by ferry boat. The character of the northern area of the island is defined by a historical district with neoclassical buildings, while the rest consists mostly of green open spaces. For these reasons, the proposal for Governor's Island was to prepare a pattern of development for both a wetland park and a small university campus. The existing buildings, possibly retrofitted with low-cost interventions, could accommodate some of the university departments. This way, the investment made by the university would trigger new economic processes, and would finance a process of re-naturalisation. In fact, the southern part of the island, more subject to future flooding, would be partially given back to nature with the reinstatement of a wetland environment. An abacus of differently landscaped open spaces, and a series of experimental pathways would define the different areas of the campus. The combination of programs would then combine an every-day use of the island by the students with an affluence of visitors exploring the new Governors Island park during event days and weekends.

The strategies presented for the second case study of the Studio project respond to the decaying character of Cohoes, and the resultant 'doughnut pattern' of an emptied downtown and a dispersed settlement pattern to its extents. Cohoes belongs to an axes of former textile industry centres in Upstate New York, tied together in a linear system by the Hudson river. The reversed pattern came about once the industrial activities were dismantled: the downtown centre, formerly connected to the industrial sites along the river, was progressively emptied as the constantly decreasing, and now elderly population, moved out in the peripheries. Moreover, since 1970 and the dismantling of the area's industrial activities the population has decreased by $25 \%$ and the unemployment rate has increased by $6 \%$ in less than 50 years. The current cost of gas has rendered this cardependent system unsustainable for the population of Cohoes, while the absence of a 
downtown centre reflects an economic stagnation that has resulted in a social pattern of isolation and a complete absence of any 'common good' and public activity. The project proposal looks for opportunities in the existing downtown area- and develops a series of strategies focused on the reprogramming and conversion of the existing 'left-over' open spaces- in order to turn them into 'public spaces'. The strategies are considered as articulated into a time line, in which the objectives are implemented at different time intervals. The mechanism aims to trigger several micro processes within the project, in order to follow through on the shrinking pattern in a more positive, ecologic way. In a first phase, the public transportation network is re-designed in order to make the city's historical downtown more accessible from the peripheries and also better connected internally speaking. Car traffic would consequently be reduced, as the new public transportation routes would permit pedestrian movement. In order to create a network of public activities, the project proposes the reprogramming of a series of existing unused open spaces, including redundant parking lots, space left between buildings and leftover green areas, in order to create a system of open spaces that can be efficiently used by the city's inhabitants. This network of continuously productive 'urbanscapes', reconnects the disjointed layers of pathways, open spaces, public facilities and green areas into a new system. As the existing under-utilised green areas become patches of urban agriculture for community use, the redundant parking lots adjacent to the existing few commercial services are retrofitted with the addition of necessary public services and the activation of recreational events and turned into new congregating areas for the community. The waterfront area is involved in the network of urban activities and turned into a large productive park, proposing urban agriculture as a way of envisioning a possible return of economic activities to the town's historical centre, triggered by a new, productive use of the existing public spaces.

\section{Conclusions}

The theoretical contributions analysed in the first place, including the "city in the city" by Oswald Mathias Ungers and the Landscape Urbanism discussion, suggest an approach to post-industrial shrinking cities that should now be verified through the analysis of the projects presented. This way, the paper can be developed into a theoretical tool on the revitalisation of shrinking cities through the design of an armature of public spaces. The projects presented, in fact, suggest a series of considerations on the Landscape Urbanism theoretical discussion that can be organised into a set of macro-themes that I have defined as: 'working on a network of open spaces', 'the necessity of a multi-scalar approach', 'a toolkit of interventions', 'accessibility as a must', 'how to define a network of public spaces?', 'the necessity of an economic engine', and 'a polycentric urban landscape'. What this paper discusses more generally is the potential that lies in the transformation of under-utilised open spaces into networks of public spaces in order to revitalise cities with a decaying economy, loss of population, and entirely abandoned workers' housing quarters. This implies an understanding of the idea of 'network' and of the city as a system of relations. For this reason, these conclusions introduce Space Syntax as an additional theoretical tool to complement the Landscape Urbanism discussion. 

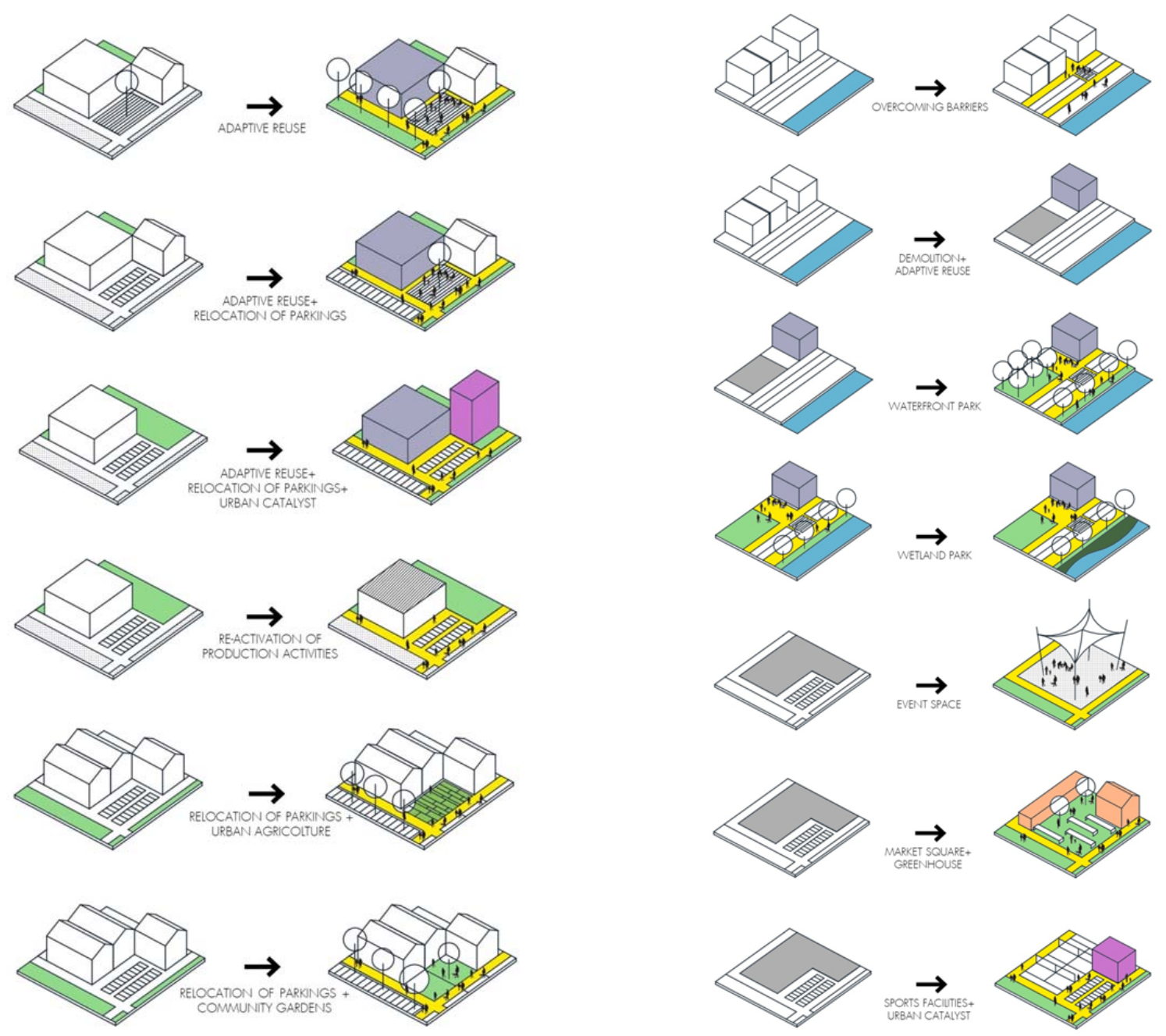

Fig. I-2. A toolkit of strategies for the revitalization of a decaying post-industrial town.

\section{Working on networks of open spaces.}

Many theoretical contributions, including the Landscape Urbanism discussion, suggest that the city has to be observed with a reversed perspective. In fact, dispersed urban conditions such as those seen in post-industrial American cities cannot be approached through conceptual tools that once belonged to European, historic cities. The overabundance of under-utilised land, within a dispersed urban environment, requires one to look at the city through its open spaces rather than its built environment. This discourse applies to post-war urban conditions, such as Berlin, as well as to shrinking cities. Shrinking cities are, in some cases, comparable to dispersed urban landscapes. In the case of the city of Detroit, as well as post-war Berlin, the urban fabric is fragmented and a strategy of 'filling the voids' doesn't seem practicable. This also implies a different interpretation of public spaces. In fact, dispersed urban conditions suggest that we ought to understand public spaces not only as squares and parks, but also as systems of interconnections. As explained by Charles Waldheim, in the city of Barcelona, the macroscale infrastructures of mobility are, themselves, public spaces. The interpretation of cities 
as systems of flows suggests an approach on public spaces focused on networks and movement as well as on more "static" public spaces. As Bill Hillier (2007) explains, the open spaces of a city constitute a system of convex spaces and linear spaces, as people interact in convex spaces but also move in lines, and movement itself has to be considered as a form of interaction.

\section{The necessity of a multi-scalar approach.}

The strategies of the two school projects presented belong to different scales of intervention. The projects propose both very small scaled interventions, such as the design of a network of small scale community gardens, as in the case of Cohoes, and macro-scale designs, as in the case of Governors Island. Similarly, the strategies of Ecosistema Urbano in Philadelphia consist of a series of small-scaled, interstitial interventions, while the Park of la Villette is a macro-scale intervention. For the purpose of this discussion, I will introduce another concept of Space Syntax. The theory explains the difference between the 'foreground network', which consists of the armature of spaces connected to the economic activity of the city, and the 'background network' consisting of small-scaled, residential fabric. (Hillier, Vaughan, 2007). Every city presents both networks and this suggests that turning open spaces into public spaces means working on both these two networks at the same time, by activating macro-scale projects such as la Villette but at the same time, developing a finer grain of pocket parks, community gardens, small clusters of activities and public squares, at the local scale. Moreover, this also suggests that a micro-scale network of public spaces should be inserted into a well-designed macro-scale network of connections. At the scale of the city, one should look at parks, like the one at la Villette, as successful interventions, but at the scale of the neighbourhood, a city should provide a finer grain of public spaces and 'urban catalysts', addressing the livability of the area, and allowing pedestrian movement and human interaction. As explained in the previous point, both the two scales of intervention need to be developed in a systemic way, as networks of spaces, as opposed to isolated, fragmented interventions. This is done through the reconfiguration of mobility, in particular through public transportation, in order to reduce car dependency.

\section{A toolkit of interventions.}

From all the projects presented in the paper, I have extracted a toolkit of possible interventions for the revitalisation of a shrinking city through the design of its public spaces. (fig. I) The diagrams presented summarise a series of possible strategies to reconfigure under-utilised open spaces to create active, lively urban spaces. For instance, as in the case of Barcelona, the waterfront can be reconnected to the downtown area by overcoming existing barriers. Empty lots, such as in the case of Philadelphia, can be transformed into pocket parks, urban agriculture, event spaces, etc. Where there are few existing public services, as in the case of Cohoes, these can be implemented by urban catalysts and integrated within a public square. An ideal intervention (fig. 2), summarising all of this strategies in one project, would then involve: selective demolition, the reconfiguration of certain empty lots into pockets of green land, a productive urban landscape, event spaces, the adaptive reuse of existing abandoned buildings and the insertion of 'urban catalysts' to activate social encounters and economic triggers. All the reconfigured lots should be then tied together by public transportation networks, and pedestrian and bicycle lanes. In a way, this 'urban acupuncture' strategy on open spaces is 
a modest intervention: it requires bottom-up strategies for the reconfiguration of underutilised land and buildings and the reorganisation of existing public transportation in order to create a pattern of accessibility within an armature of open spaces.

\section{Accessibility as a must.}

Within my ideal toolkit of interventions I have included the overcoming of barriers between the city and its waterfront. In such cases, as in the project by Oriol Bohigas on the city of Barcelona, the barrier is a physical object- the freeway running parallel to the city's waterfront- and the strategy for overcoming it is actioned through the construction of infrastructures, such as pedestrian bridges, allowing access. In the case of Detroit, the freeways are physical barriers cutting the city centre in pieces. In other cases, as Space Syntax explains, the "barriers" to human interaction are more invisible. They depend on the structure of the network of streets, which can result in integrated or segregated patterns. As the shape of the network influences movement and co-presence (Hillier, Vaughan, 2007), an intervention on the existing network can improve the patterns of human interaction. An analysis of the existing conditions can be employed in finding the issues to be resolved in terms of flows and accessibility. In fact, the analysis with Space Syntax allows one to pick up not only a general structure of the city, but also shows both the most accessible street segments for all kinds of movement - pedestrian and vehicularat all scales, and the segregated street segments (Hillier, Vaughan, 2007). This analysis can therefore identify areas necessitating interventions related to the 'reconnection' of an existing network of streets. Moreover, the analysis can be employed into verifying different possible scenarios of intervention by mapping them within the context of the existing networks. This allows one to select the best intervention in terms of the creation of accessibility at all scales.

\section{How to define a network of public spaces?}

Not all open spaces are destined to become public spaces. In general, one should work with what is already there by reinforcing existing centralities. Potential new centralities, on the other hand, are not always 'visible'. Bill Hillier (2007) argues that all cities present a foreground network of centres at all scales. For this purpose, Space syntax provides a strategic tool through which analysing existing networks, picking up the general structure of the city, and understanding the existing pattern of centralities is made possible. In our particular case, when talking about the toolkit of interventions, the analysis with space syntax could suggest which network should remain accessible to cars only and which other network(s) should be reconfigured for pedestrian movement, achieved by creating a system of interconnections via public transportation and the activation of bicycle lanes, pedestrian pathways, etc. Moreover, it could also suggest how to distribute what I called the 'urban catalyst', the adaptive reuse of buildings, and the other urban functions: those could be located in correspondence with existing networks of very accessible streets in order to create a sort of 'main street' within the project.

\section{The necessity of an economic engine}

Urban acupuncture seems to be a very sensible approach, but is it really possible to revitalise a city with these strategies? How does an open space become transformed into a lively, vibrant public space? It seems to me that an approach focused on designing public spaces within a decaying urban area can result in failure if no actual economic 
revitalisation of the city or densification of human activities, jobs, production and economic engines are gained. For example, nowadays, the city of Detroit presents acres of abandoned land within the urban centre and wealthier quarters in the suburbs. But how could it be possible to revitalise the urban centre with this toolkit of strategies whilst attracting people to actually live and work there? What kind of economic trigger could be attracted in order to provide jobs and an actual revitalisation of the city centre?

Contemporary discussions envision a possible reactivation of the industrial compounds of cities like Detroit, in order to reactivate the economy and allow other kinds of interventions in the city. The project on Cohoes, for instance, proposes the location of a server farm as an economic trigger and a generator of jobs for the surrounding area. All this suggests, as a conclusion, that production activities in the city centre be reclaimed, not only in terms of agriculture but also in terms of artisanal production and green industries. These kind of ideas question the Landscape Urbanism approach of transforming all former industrial sites into parks. It would be necessary to study and envision healthy patterns of accessibility, both at the global and the local scale, in order to properly locate the economic engines, or 'urban catalysts', on the envisioned networks of interventions. Public and private transportation flows should be reconfigured in order to intensify economic activities. Space Syntax, for instance, provides tools through which designing networks of interconnection according to socioeconomic factors is made possible. In particular, it allows one to make previsions in terms of how certain networks would function, compared to others, to create patterns of accessibility which allow the development of lively urban spaces. In this way, Space Syntax could be employed to verify macro-scale as well as micro scale networks, determining, for instance, what would be the most accessible paths within the small scale network best developed into cycling or pedestrian pathways and accompanied by the insertion of urban catalysts, economic activities and public spaces. Those selected pathways, in other words, could then consist of the areas to be revitalised through the set of "urban acupuncture" strategies derived from the analysed projects and summarised in the diagram.

\section{A polycentric urban landscape}

After all these considerations, when approaching the issue of the revitalisation of a shrinking city, it seems to be necessary, first of all, to think of a methodology that involves the whole structure of the city. In fact, intervening on particular areas such as waterfronts or dismantled industrial sites can have fragmented results, if the whole urban system appears as disconnected and dispersed. Conversely, it is possible to envision strategies that are related not only to the retrofitting of existing open spaces, but which are also geared towards the development of a 'healthy' urban structure in terms of its system of relations. The project by Oswald Mathias Ungers on Berlin, as well as Charles Waldheim's ideas for the city of Detroit described into "Stalking Detroit", suggest that we approach dispersed urban environments by developing a polycentric urban landscape. Density seems to be a requirement for urban life, so, starting with the idea of selective demolition, this could be taken into consideration in order to create denser areas rather than a homogeneous, low density urban landscape. The form of a polycentric urban landscape could be implemented through policies geared towards the relocation of people from abandoned, unhealthy urban areas, in terms of crime rate, poverty, unemployment, etc, into revitalised urban areas. Learning from the concept of a polycentric urban landscape, density could be increased in certain areas in which, 
subsequently, it could be possible to intervene with the presented toolkit of strategies at the neighbourhood scale. In other words, the theoretical contributions analysed suggest that we envision large-scale urban strategies, such as the creation of a polycentric urban landscape, in which we apply a set of strategies at the neighbourhood scale. In both scales of intervention, it would be necessary to create new networks, or reinforce existing ones, through the development of a system of connections within the existing and renovated centralities. The interconnectedness of the proposed system of interventions, at all scales, constitutes, as previously explained, a fundamental tool for the success of a project on public spaces.

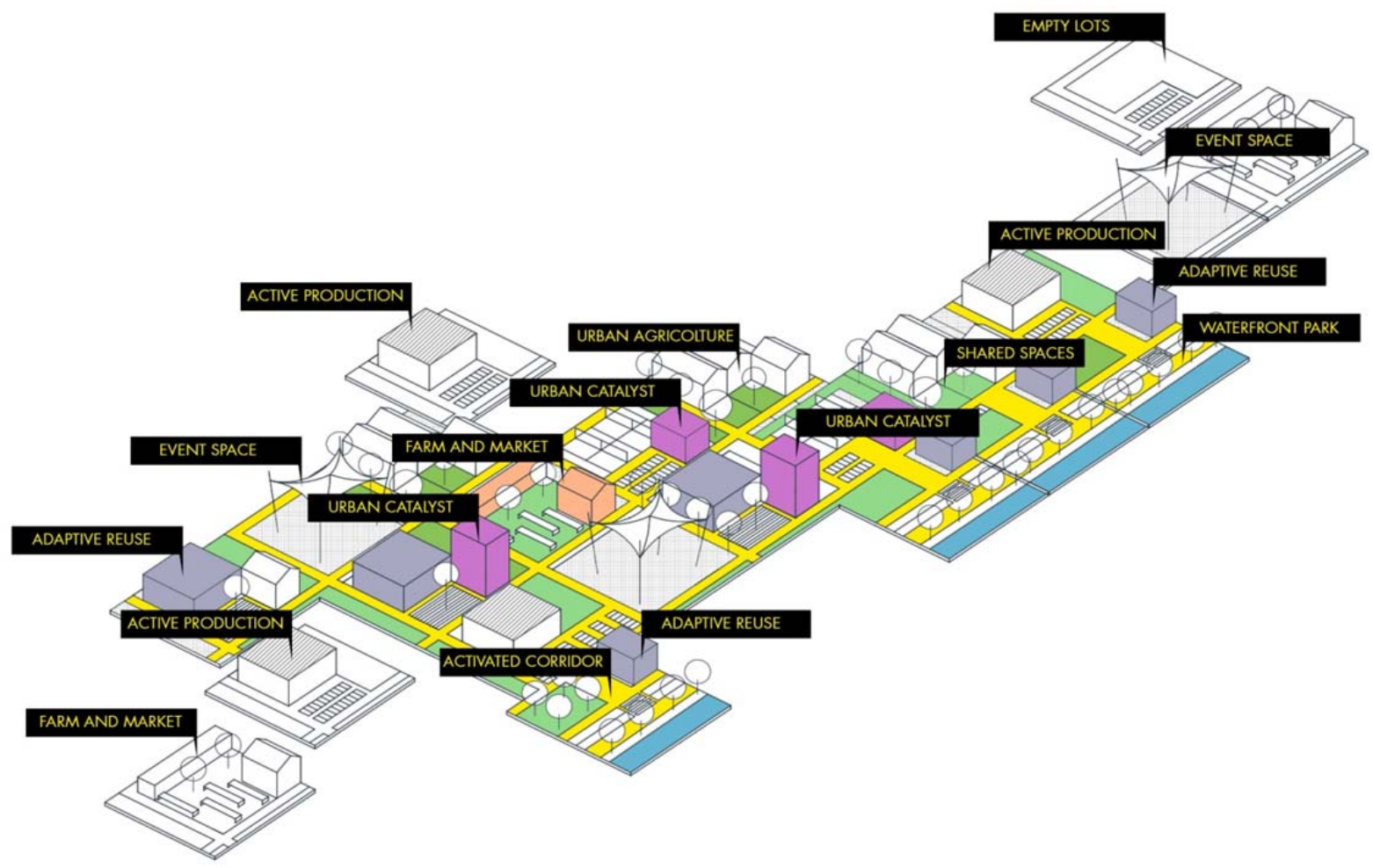

Fig. 3. A toolkit of strategies for the revitalization of a decaying post-industrial town.

\section{Acknowledgments}

This paper is dedicated to the memory of Moji, a very passionate Professor who dedicated her life to exploring new means of practicing Urban Design. I would also like to thank my work group for the Urban Design Studio II during the Master in Architecture and Urban Design, in 2008: Shreya Malu, Nu Xuo, Maria Alicia Bechdach. My special gratitude goes to Maria Alicia Bechdach for the amazing time we had working together throughout the whole year.

\section{References}

Cepl, J., (2006) “Oswald Mathias Ungers's Urban Archipelago for Shrinking Berlin”, in Oswalt P., (editor), Shrinking cities. Volume 2-Interventions, Hatje Cantz. 
Corner, J. (2006), “Terra Fluxus”, in Charles Waldheim (editor), The Landscape Urbanism Reader (pp. 021-033) New York: Princeton Architectural Press.

Daskalakis G.., Waldheim C., Young, J., (200I), Stalking Detroit, Actar.

Hillier, B, Vaughan L., (2007) “The city as one thing”, in Progress in Planning, 67(3): 205-230.

Oswalt, P. (2005) Shrinking cities, volume II: Interventions. Ostfildern-Ruit : Hatje Cantz.

Pluviano, A., Psarra, S., (20/4), "Turin and Detroit: The Role of the Road Network in the Evolution of the Industrial and Post-Industrial City: 1920-2010" in Cavallo, R., Komossa, S., Marzot, N., Berghauser Pont, M., Kuijiper J. (editors) New Urban Configuration, Delft University Press.

Shane, G. (2005), Recombinant Urbanism. Conceptual Modeling in Architecture, Urban Design and City Theory. John Wiley

Shane, G. (2006) "The Emergence of Landscape Urbanism”, in Charles Waldheim (editor), The Landscape Urbanism Reader (pp. 055- 067) New York: Princeton Architectural Press.

Shannon, K. (2006) "From Theory to Resistance. Landscape Urbanism in Europe", in Charles Waldheim (editor), The Landscape Urbanism Reader (pp. 14I-16I) New York: Princeton Architectural Press.

Smedt, M. (2002) "Grid, Casco, Clearing and Montage", in Robert Shafer and Claudia Moll About Landscape: Essays on Design, Style, Time and Space (pp. 132-33) Munich: Callwey Birkhauser.

Waldheim, C. (2006) “Landscape as Urbanism”, in Charles Waldheim (editor), The Landscape Urbanism Reader (pp. 035-052) New York: Princeton Architectural Press. 